little to criticize in the statement of fact-perhaps nothing that would not lay me open, in view of the book's purpose, to the charge of quibbling.* $\mathrm{He}$ has presented these conceptions with a wealth of illustration, and in a style that is always pleasing and often of rare beauty and power. He has developed many and often surprising connections and analogies with apparently remote fields of inquiry. I venture to say that no one, be he professional mathematician or educated layman, can read this book without feeling its stimulating and thought-provoking character, provided only he be philosophically minded. A man not interested in meditating on the general aspect of things would perhaps find the book dull. But what a lot of the joy of life such a man must miss.

J. W. Young

\title{
TWO TRANSLATIONS OF ARCHIMEDES
}

Les Euvres Complètes d'Archimède. Traduites du Grec en Français avec une introduction et des notes. By Paul Ver Eecke. Paris and Brussels, Desclée, de Brouwer et Cie., 1921. lx +553 pp.

Kugel und Zylinder von Archimedes. Uebersetzt und mit Anmerkungen versehen. By Arthur Czwalina-Allenstein. No. 202 of Ostwald's Klassiker der exakten Wissenschaften. Leipzig, Akademische Verlagsgesellschaft, 1922 . $80 \mathrm{pp}$.

In considering these two recent evidences of Belgian and German scholarship it may naturally be asked why a new edition of the complete works of Archimedes, or even of a single treatise, should be thought worthy of publication at this time, particularly in view of the fact that we already have the monumental edition by Heiberg, with its recent revision; the

* In the interest of removing minor blemishes in a future edition, attention may be called to the following: In the group definition of the geometry of shape on p. 218 reference should be to "each and all the transformations of the similitude group" and no others; on p. 267, line 7 from the bottom, after the word "field" the restriction $\left(n \neq n^{\prime}\right)$ should be added; on p. 329 the statement that a plane of circles is "as rich in circles as in point-triads, as rich in circles as ordinary space in points" is erroneous unless the point-triads be restricted to those formed from points of a line, and is open to misunderstanding, since it leads rather easily to the erroneous idea that dimensionality is a function of the cardinal number of a class rather than of the arrangement of its elements. The extended treatment of the concept of limit seems to me unnecessarily involved and difficult; this portion of the book is hard reading even for one familiar with the concept.

Very few typographical errors were noticed. These occur on p. 136, line 5 from the bottom; on p. 175, line 4 from the bottom; on p. 243 lines 9 and 10 ; on p. 271, line 11 ; and on p. 377, line 12 . 
English edition, with a biographical study, by Heath; the French edition of Peyrard; the German translation of Nizze, and numerous other translations, more or less complete, by such earlier writers as Tartaglia, Venatorius (Thomas Jaeger), Commandinus, Revault (Rivaltus), Maurolycus, and Torelli.

There are various legitimate answers to the question, depending upon the point of view implied. In the first place, the older translators were usually limited to a single manuscript of each work, and that not a very reliable one; textual criticism, in the modern sense, was unknown. In the second place, Heiberg himself, the greatest student of Greek mathematical manuscripts who has undertaken to give a definitive text of Archimedes, based upon the most trustworthy codices, found that the discoveries of Papadopoulos Kerameus, in 1899, necessitated an extended revision of his own edition, and this revision was published in 1913-1915. It follows that all of the earlier translations must now be looked upon as obsolete, if we wish for correct versions. The significance of this statement may be appreciated by comparing the text of Peyrard (Paris, 1807), for example, with that of Heiberg or with the ones under review. Peyrard gives as the first proposition of the Sphere and Cylinder a statement which belongs with the fifth postulate of Archimedes, the second proposition being the first as set forth by modern critical writers. Similar variations will be found throughout all of the older editions, but naturally the greatest changes are in the Stomachion, the Method, and the Floating Bodies, all of which have come to light in whole or in newly discovered portions within the last twenty years.

The third justification for a new translation is seen in the general method employed in setting forth the mathematical works of the ancients. Just how far should a translation be literal, and how far should it seek to preserve the form in which the original is cast? The answer to this question depends upon the purpose of the translator. In Heiberg's version he gives the Greek text as it appears in the best manuscripts extant, using the modern forms of the letters and the alphabetic numerals. The text gives, therefore, a correct idea of the original form of statement. In his Latin translation, however, he breaks away from this original form and introduces such modern symbols as appear in the lines

and

$$
\begin{gathered}
\Delta \Gamma+\Gamma B>\Delta B, \\
\mathbf{E H}: \mathbf{H Z}=\mathbf{A} \Gamma: \mathbf{A} \theta,
\end{gathered}
$$

$$
\angle \mathrm{NH} \Gamma<2 \Lambda \mathrm{KM} \text {. }
$$

When Heath prepared his edition he did the same; but he went even further, arranging the proofs still more after the manner of the modern textbook maker.

As to which of these methods is to be preferred, the reader's preference must be final. The Heath plan is unquestionably the easier for one who is simply searching for the mathematical principles involved; but the method used by Heiberg in the Greek text is the better if one wishes to attune his mind to that of the Greek scholar. Most students who have seriously studied Euclid and Apollonius and Archimedes, for example 
marvel no doubt at the clarity of the reasoning as set forth in rhetorical form, and at the ability of the Greek mind to accomplish, with no special mathematical symbolism, the results that appear in the classical works of these men. For such students the text which most nearly represents the original is the better; but for the general reader, who is not particularly interested in the mental processes of the Greek, the modern arrangement of proofs, with our common symbols, will be the more simple.

In the two books under review the reader will find the original Greek method set forth at its best in the translation of M. Ver Eecke. It is a model of elegant French and of close rendition of the original text. The scholarly world is greatly indebted to him and to his publishers for their "labor of love." A comparison of the French text with random selections from the Heiberg version shows that the translation has been made with elegance and precision.

The version of Dr. Czwalina-Allenstein is less pretentious, being limited to the Sphere and Cylinder. It consists of a careful translation of Heiberg's Latin text, with the modern symbols there used. Instead, however, of displaying the equations and inequalities so that the eye grasps them easily, the translator has run them in with the text. This was doubtless due to the desire to save space, although it is not probable that the size of the book is thereby reduced by more than a couple of pages. The result is that we have neither the original form of expression as seen in the Greek version of Heiberg and in M. Ver Eecke's translation, nor the modern display arrangement as seen in Heath's edition. Nevertheless we have every reason to be thankful for such an accurate piece of work and for its publication in a form that makes the Sphere and Cylinder available at a nominal price for all German readers. Indeed, it is with some feeling of envy that one considers the advantages that German scholars have over us in the possession of the Ostwald Klassiker in such worthy translations.

On the whole, each of the books under review serves a worthy purpose. The smaller of the works serves such a purpose in that it places in the hands of all who are interested in the subject one of the greatest mathematical classics of the Greeks, and at a price which, even in these troublous times, is insignificant. The more pretentious work of M. Ver Eecke serves a more distinguished purpose, but perhaps no more important one, in that it gives us the first complete modern translation of the works of Archimedes, based upon the latest discoveries and the best textual criticism, and in that this translation gives us the form of the original treatises so that we can more easily place ourselves en rapport with the mind of the great genius who gave them to the world.

David Eugene Smith 